\title{
Bioactive Natural Substances from Marine Sponges: New Developments and Prospects for Future Pharmaceuticals
}

\author{
Stamatios Perdicaris ${ }^{1}$, Thomais Vlachogianni ${ }^{2}$ and Athanasios Valavanidis ${ }^{2 *}$ \\ ${ }^{1}$ Faculty of Pharmacy, Department of Pharmacognocy and Natural Product Chemistry, University of Athens, University Campus Zografou, 15784 Athens, Greece \\ ${ }^{2}$ Department of Chemistry, Laboratory of Organic Chemistry, University of Athens, University Campus Zografou, 15784 Athens, Greece
}

\begin{abstract}
In the last decades researchers of natural products chemistry focused their research in a wide variety of bioactive compounds from marine species. Marine sponges (Porifera) have been ranked very high in the priority of natural product research because the discovery of a wide range of bioactive chemical components and secondary metabolites with potential pharmaceutical applications gave promising results. These discoveries have attracted the attention of pharmaceutical chemistry experts, cell biologists, chemists of natural products and medical practitioners. Since the 1950s, when a number of the first publications appeared in the scientific literature, some bioactive natural chemicals from marine sponges gave successful examples of pharmaceuticals. Initial experimental results suggest that sponges have the potential to provide future drugs against important diseases, such as cancer, a range of viral diseases, malaria, and inflammations. At the same time scientists studied the molecular mode of action of most sponge-derived metabolites and their mechanism of action were elucidated for their therapeutic potential in a variety of diseases. This review aims at describing some of the most highly cited reviews of the last decade on sponge-derived bioactive compounds and the most promising substances extracted and isolated from marine sponges for pharmaceutical applications. The review is covering mainly new developments of the last five years in the field of marine sponge metabolite research and important findings for bioactive compounds from in vitro, in vivo and clinical studies for therapeutic drug applications.
\end{abstract}

Keywords: Sponges (Porifera); Marine sponges; Natural products; Natural metabolites; Bioactive components; Pharmaceutical products; Marine drugs

\section{Introduction}

Marine sponges for the past decades have been considered as a very fertile field for the discovery of bioactive natural chemical substances with respect to the diversity of their primary and secondary chemical components and metabolites. The biological effects of new metabolites from sponges have been reported in a number of scientific research papers. Highly cited reviews have been published in the last decades concerning the sponge-derived chemicals with bioactive properties which have the potential to be used for future pharmaceutical applications [1-5].

Scientists have ask the obvious questions, what is the ecological role of sponge metabolites and why sponges produce so many bioactive components that can be useful to treat a great range of human diseases? Studies in the last decades extracted, separated and tested a large number of different primary and secondary metabolites in marine sponges. Also, a numbers of research projects investigated the molecular complexity of the compounds and their biosynthetic pathways that can be regarded as an indication of their importance for the survival and defence of sponges in the evolutionary process $[6,7]$.

Sponges (Porifera), as primitive filter-feeders, have a high frequency of bioactive components for their chemical defences against environmental stress factors such as predation, overgrowth by fouling organisms or competition for space. Studies showed that the highest concentration of toxic or antioxidant sponge metabolites are found in habitats such as coral reefs that are characterized by intense competition and feeding pressure from carnivorous fish. The adaptive significance of sponge's chemical constituents is derived from the observation that their chemical defences are highly effective against most species of fish and a group of shell-less gastropods, the nudibranchs that are feeding on sponges and sequestering their chemical armoury [8].

\section{Marine Sponges: Adaptive Evolution, Ecology and Metabolites}

Marine sponges through evolutionary and ecological long term changes often contain diverse microbial communities (bacteria, archaea, microalgae, fungi) which comprise as much as $40 \%$ of the sponge volume and can contribute significantly to host metabolism (e.g., via photosynthesis or nitrogen fixation). The ecological and evolutionary importance of sponge-microbe associations can be mirrored by their enormous biotechnological potential producing a great range of bioactive metabolites [9]. The benefits of the secondary metabolites in sponges can be tested by the presence of natural antifouling products. Sponges safeguard their water-pumping capacity by avoiding the formation of biofilms or avoiding the settlement of barnacles or bryozoans on their surface $[10,11]$.

Sponges produce high levels of cytotoxic chemicals by the emission of mucus containing toxins in order to create a clear zone around it and push back other marine species. The level of cytotoxicity of some sponge products is high enough to even create a bare zone around the sponge. This behavior allows the sponges to conquest densely populated rocks or corals and compete with faster growing organisms, but it is striking that the sponge can selectively use its poisons without selfdestruction. Secondary metabolites can protect the organism against predation, which is especially important for physically unprotected

*Corresponding author: Valavanidis Athanasios, Professor, Laboratory of Organic Chemistry, Department of Chemistry, University of Athens, Greece, Tel: 00-30-210-7274763; Fax: 00-30-210-7274761; E-mail: valavanidis@chem.uoa.gr

Received September 12, 2013; Accepted October 21, 2013; Published October 27, 2013

Citation: Perdicaris S, Vlachogianni T, Valavanidis A (2013) Bioactive Natural Substances from Marine Sponges: New Developments and Prospects for Future Pharmaceuticals. Nat Prod Chem Res 1: 114 doi: 10.4172/ 2329-6836.1000114

Copyright: (c) 2013 Perdicaris S, et al. This is an open-access article distributed under the terms of the Creative Commons Attribution License, which permits unrestricted use, distribution, and reproduction in any medium, provided the original author and source are credited. 


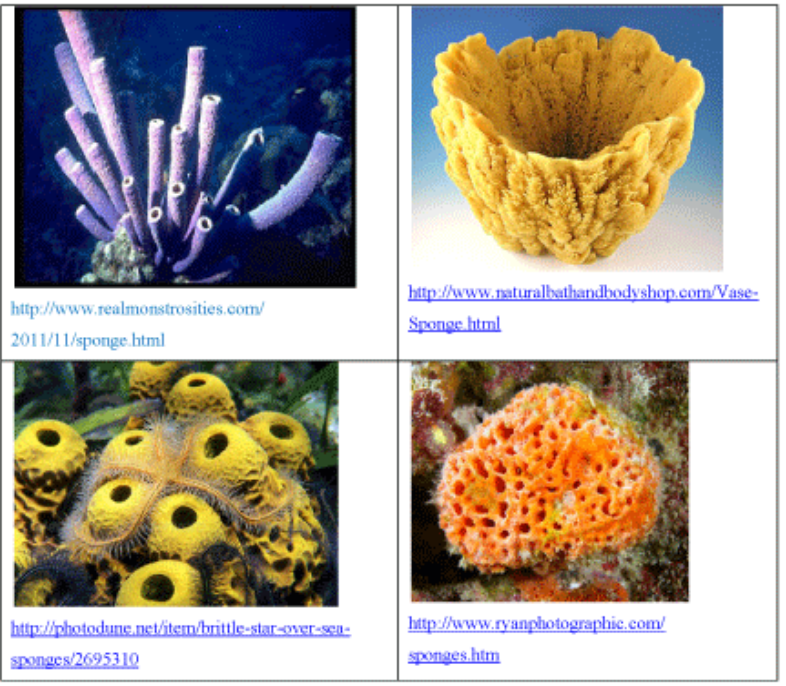

Figure 1: Photos of various sponges. Sponges are animals of the phylum Porifera (meaning "pore bearer"). They are multicellular, heterotrophic, lack cell walls, produce sperm cells and are hermaphroditic.

sessile organisms like sponges [11-13] (Figure 1).

Scientist has discovered more than 5,000 species but it is thought that there are more than 8,000 marine sponges on Earth. Sponges constitute the phylum Porifera, defined as sessile metazoans (multicelled immobile animals) that have water intake. There are also a few carnivorous sponges. All known living sponges can remold their bodies, as most types of their cells can move within their bodies. Sponges have no nervous systems, their middle jelly-like layers have large and varied populations of cells, and some types of cell in their outer layers may move into the middle layer and change their functions [14-16].

\section{Marine Sponges and Natural Chemical Components}

Marine sponges have been ranked at the top with respect to the discovery of bioactive compounds with potential pharmaceutical applications. The diversity in chemical structures of sponge-derived metabolites is related to an equally diverse pattern of activities. Scientists in the field of natural products chemistry and research suggest that sponges have the potential to provide future drugs against important diseases, such as a range of viral diseases, malaria, inflammations, immunosuppressive diseases and various malignant neoplasms [5,17-19].

Early investigations gave rise to broad surveys of marine life for novel natural products with useful biological properties. Scientific efforts focused through a series of agency-supported programs, with the National Cooperative Drug Discovery Program of the National Cancer Institute (NCI) in the USA playing a key role. This program recognized that the rich chemistry of marine organisms was not translating into useful drug leads largely because of poorly developed connections between academic researchers and the pharmaceutical industry [20]. By forging collaborative interactions between groups of academic investigators and pharmaceutical companies as well as the NCI, a critical mass of natural product materials, modern assays and development know-how was assembled. These important data lead into several clinical trials of natural products from plants and animals [21].

Natural products have been the major sources of chemical diversity for starting materials for driving pharmaceutical discovery over the past century. In the last decades many natural products and synthetically modified natural product derivatives have been successfully developed for clinical use to treat human diseases. But the pharmaceutical companies decreased significantly their activities in natural product discovery and in cooperation with biotechnological companies started work in the fields of combinatorial biosynthesis, genetic engineering and metagenomics. But these approaches had limited success. Thus, natural product research has been revived in the last few years with many new interesting discoveries of bioactive molecules and drug applications [22-24].

It was proved that marine sponges produce an enormous array of antitumor, antiviral, anti-inflammatory, immunosuppressive, antibiotic, and other bioactive molecules that have the potential for therapeutic use. Studies showed that different components affect the targeted disease by different mechanisms (e.g., microtubule stabilization or interaction with DNA to combat tumors). Natural chemical products that can act as inhibitors of transcription factors may be effective against both malignant neoplasms and viral diseases. Most bioactive metabolites from sponges proved to be inhibitors of certain enzymes, which often mediate or produce mediators of intracellular or intercellular messengers involved in the pathogenesis of a disease [25-27].

More than 15,000 marine products have been isolated and tested until the last 20 years until 2012. Sponges have been the champion producers with large diversity of natural components. In 2011 the total number of natural products was 1152 (for the last year we have data). The new natural chemical components from phylum Porifera (sponges) has increased slightly from previous years, to 269 new compounds were reported, mainly due to several studies reporting large numbers of new metabolites from single collections The chemical diversity of sponge natural products is remarkable, including unusual nucleosides, bioactive terpenes, sterols, cyclic peptides, alkaloids, fatty acids, peroxides, and amino acid derivatives (which are frequently halogenated) [28].

For this review we have surveyed the new discoveries of natural products derived from marine sponges for the last five years and their potential for drug applications.

\section{Types of MarineSponge Metaboliteswith Pharmaceutical Applications}

The scientific literature contains numerous examples of bioactive compounds from marine sponges that were tested for the potential of antiinflammatory, hypocholesteromeric, antitumour, immunosuppressive, neurosuppressive, muscle relaxants, antiviral, antimalarial, antibiotic and antifouling properties. In the present review we aimed to cover the most important scientific papers (selected from the vast literature on the field) and reports of the last five years under different properties.

\section{Antoxidants, Scavengers of Reacive Oxygen Species (ROS) and Antiinflammatory Compounds from Marine Sponges}

Many studies in the last few years discovered bioactive compounds from marine sponges that were classified for their antioxidant, radical scavenging and anti-inflammatory properties. A study analysed four marine sponges; Smenospongia (SP1), Callyspongia (SP2), Niphates (SP3), and Stylissa (SP4) that were collected from the Red Sea at Egyptian coasts. The sponges' extracts exhibited diverse inhibitory effects on oxidative stress indices and carbohydrate hydrolyzing enzymes in linear relationships to some extent with concentration of inhibitors (dose dependant). The extracts of sponges showed potent-reducing power. 
Chemical characterization of sponges found phthalates, linoleic acid, sitosterol and cholesterol [29].

Among novel natural antioxidants, marine sponges are highly ranked source. A number of metabolites derived from marine sponges, such as indole derivatives, aromatic alkaloids, aromatic polyketides, and phenolic compounds have exhibited strong antioxidant potential compared to vitamin $\mathrm{E}$ and ascorbic acid [30,31]. Aromatic polyketides isolated from marine sponge-derived fungus Aspergillus versicolor have shown significantly higher antioxidant capacity than that of butylated hydroxytoluene (BHT) [32]. A scientific study reported that marine sponge--derived yeasts are capable of producing antioxidative indole derivatives which can scavenge free radicals and ROS [33]. These findings were very attractive since these sponge microbes are culturable, and there is a possibility of reproducing the compound in large scale [34]. In another study with the Caribbean sponge Pandaros acanthifolium the isolated steroidal glycosides exhibited high antioxidant and cytoprotective activities [35].

\section{Marine Sponges and Antitumour Compounds}

The approval of drugs from marine organisms started with ziconotide ( $\omega$-conotoxin MVIIA), that is a peptide originally from a tropical marine cone snail (U.S.A approved 2004 under the trade name Prialt) for the treatment of chronic pain in spinal cord injury. The most important antitumour compound from marine species was Trabectedin (Yondelis/ecteinascidin-743/ET-743) from a tropical sea-squirt. It was approved by the European Union in 2007 (European Agency for the Evaluation of Medicinal Products) for the treatment of soft-tissue sarcoma $[17,36]$.

In the last few years there are several other candidates from marine natural compounds in the pipeline for evaluation in Phase I-III clinical trials for the treatment of various cancers [37]. A review in 2003 collected the most important marine natural compounds which were undergoing preclinical and clinical trials (I, II, III) for anticancer activity. Among the compounds from sponges were the following: Discodermolide, Hemiasterlins A \& B, modified halichondrin B, KRN-70000, Alipkinidine (alkaloid), Fascaphysins (alkaloid), Isohomohalichondrin B, Halichondrin B, Laulimalide/ Fijianolide, 5-methoxyamphimedine (alkaloid) and Variolin (alkaloid) [38].

In recent years, new marine-derived antiangiogenic agents have been widely investigated. At least 43 marine-derived natural products and their derivatives have been reported to display antiangiogenic activities, mediated by distinct or unknown molecular mechanisms [39]

Marine sponges and their symbionts, as the most primitive of the multicellular organisms, produce a plethora of secondary metabolites. The first successful sponge-derived pharmaceutical drugs were the nucleosides spongothymidine and spongouridine which were isolated from Tectitethya crypta [40]. A derivative of these nucleosides, Ara-C (also known as 1-beta-D-Arabinofuranosylcytosine or cytarabine) is documented as the first marine derived anticancer agent that is recently used for the treatment of leukemia [41,42]. At present it is screened in clinical trials for the treatment of acute myeloid neoplasms in combination with Daunoribicin and other anticancer drugs [43].

Despite the technological advances in the last decade for anticancer drug discoveries with natural products from marine sponges, there are some difficulties in preclinical studies. A recent overview (2011) retrieved scientific papers identifying 39 compounds from marine sponges with apoptosis-inducing anticancer properties [44]. Characterizing and scaling up production of bioactive compounds from marine sponges is a slow process and several sponge-derived anticancer compounds are in preclinical and clinical trials $[45,46]$.

One natural compound from marine sponges with promising anticancer activity is Renieramycin M. Renieramycins are members of the tetrahydroiso-quinoline family that were isolated from marine sponges belonging to genera Reniera. The preclinical results reveal that Renieramycin $\mathrm{M}$ induced lung cancer cells apoptosis through p53dependent pathway and the compound may inhibit progression and metastasis of lung cancer cells [47] (Figure 2).

Monanchocidin is a novel polycyclic guanidine alkaloid isolated from the marine sponge Monanchora pulchra that induced cell death in human monocytic leukemia (THP-1), human cervical cancer (HeLa) and mouse epidermal (JB6 Cl41) cells [48] (Figure 3).

Smenospongine, a sesquiterpene aminoquinone, from the sponge Smenospongia sp. as early as 1987 and demonstrated that Smenospongine induces cytotoxic, antimicrobial, antiproliferetive and antiangiogenic activities [49] (Figure 4).

The macrocyclic lactone polyether Spongistatin 1 was isolated as in 1993 from the marine sponge Spongia sp. [50]. Spongistatin 1 was shown to inhibit mitosis, microtubule assembly, and the binding of vinblastine to tubulin thereby inducing cytotoxic cell death in numerous cancer cell lines [51] (Figure 5).

A collaborative program that was initiated in 1990 between a natural product chemistry laboratory of (University of California Santa Cruz and an experimental therapeutics laboratory of Henry Ford Hospital in Detroit) focused on the discovery and development of anticancer drugs from sponge extracts. A novel in vitro assay was used to examine 2,036 extracts from 683 individual sponges that led to the identification of

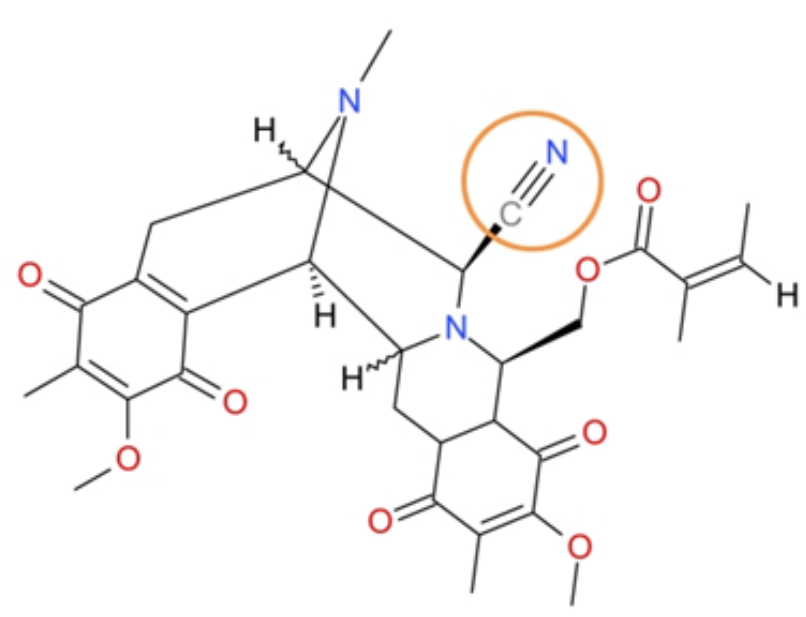

Figure 2: Structutre of Renieramycin M.

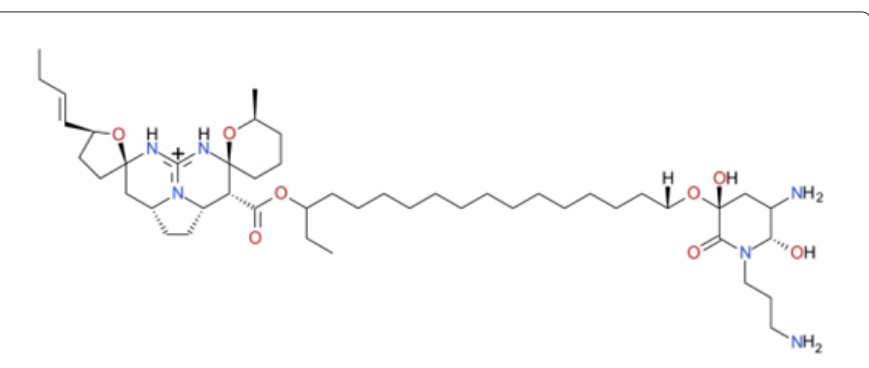

Figure 3: Structure of Monanchocidin. 
bioactive pure compounds (which were prepared in pure form and in sufficient quantities) from many sponges in treating solid tumours. The collaborative efforts and analogues led to the discovery of a number of compounds with of anticancer potential [52].

Recently, scientists purified a lectin from the marine sponge Cinachyrella apion $(\mathrm{CaL})$ that was evaluated with respect to its hemolytic, cytotoxic and antiproliferative properties, besides the ability to induce cell death in tumor cells. Results showed that the lectin induces cell death by apoptosis activation by pro-apoptotic protein Bax, promoting mitochondrial membrane permeabilization, cell cycle arrest in S phase and acting as both dependent and/or independent of caspases pathway. These results indicate the potential of CaL in medical studies for treating cancer [53].

Another component form sponges that attracted the interest of scientists as an antimour agent was Heteronemin, a marine sesterterpene isolated from the sponge Hyrtios sp., especially for its biological effects on chronic myelogenous leukemia cells. Results showed that Heteronemin was affecting cellular processes including cell cycle, apoptosis, mitogen-activated protein kinases (MAPKs) pathway and the nuclear factor kappaB (NF-kappaB) signaling cascade. This compound has potential as anti-inflammatory and anti-cancer agent [54] (Figure 6).

\section{Hypocholesterolemic Compounds from Sponges}

In the last decade it was reported that marine sponges could have been

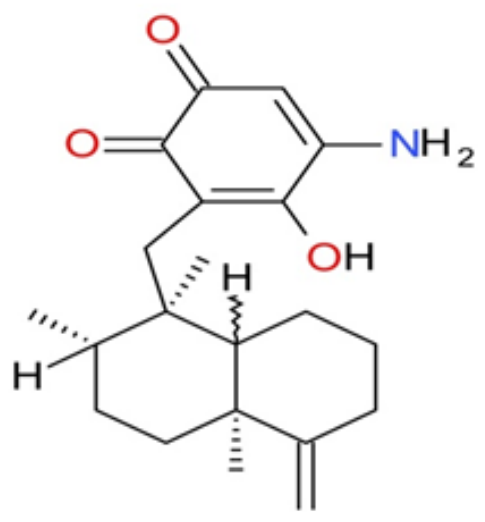

Figure 4: Structure Smenospongine.

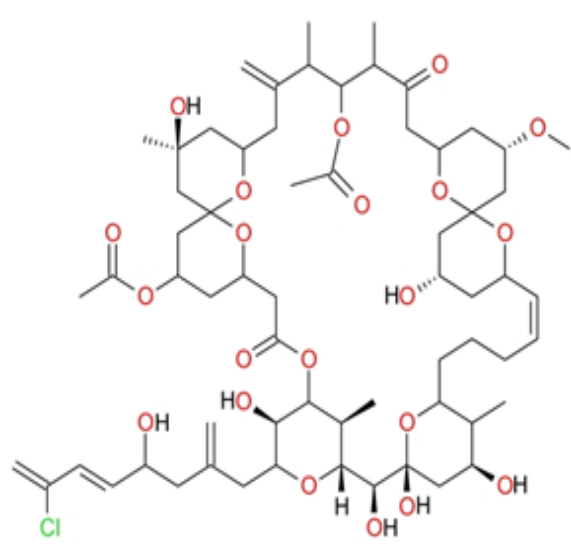

Figure 5: Structure of Spongistatin 1. a source of hypocholesterolemic compounds. For example, Spirastrella abata-derived Lyso-PAF analogues and lysophosphatidylcholines have been reported in vitro study as successful inhibitors of cholesterol biosynthesis [55,56]. Zhao et al. [57] have reported that marine sponges are a source of hypocholeste-rolemic novel lysophosphatidylcholines and thereby aroused an interest of compounds from marine sponge due to short lifespan of conventional lysophosphatidylcholines in vivo.

\section{Immunosuppressive Compounds from Marine Sponges}

In recent years natural components from marine sponges were tested from immunosuppressive properties. Immune system suppression is desired in cases of hypersensitivity to certain antigens (e.g., allergies) or organ transplantations.

Immunosuppressive compounds were isolated from a deep water marine sponge in the end of 1980s. American scientists discovered from the sponge (Bahamas) Agelas flabellrformis Carter (Agelasidae) two compounds with important immunosuppressive activity. The compounds: 4a-merhyl-5a-cholest-8-en-3 -ol and 4,5-dibromo-2pyrrolic acid were isolated from a deep water marine sponge Agelas Their structures were determined. Both compounds were highly active in suppression of the response of murine splenocytes in the two-way mixed lymphocyte reaction (MLR) with little to no demonstrable cytotoxicity at low doses [58].

Components extracted from the marine sponge Aurora globostellata (Tuticorin coast of India) showed immunomodulatory potential. The evaluation of immunomodulatory potential was performed by oral administration to Wistar rats of ethyl acetate extract of marine sponge $(200 \mathrm{mg} / \mathrm{kg})$. The results obtained indicated that extracts possesses immunosuppressant activity and can be studied further [59]. A recent investigation aimed to isolate and characterize bacteria with antimicrobial and immunomodulatory activity from an Indian marine sponge. A total of 10 marine bacterial strains were isolated from the marine sponge Callyspongia difusa (Gulf of Mannar province), which showed remarkable antagonistic activity against clinical bacterial pathogens. The findings according to the researchers suggest that the sponge associated bacterial strain Virgibacillus sp. may contribute the search for novel antibiotics to overcome infections and also for the production of potential immunomodulators [60].

\section{Antiviral Compounds from Marine Sponges}

Isolation of natural components and metabolites from sponges and screening bioactive substances led to the discovery of numerous chemicals with antiviral properties [4]. These bioactive molecules are

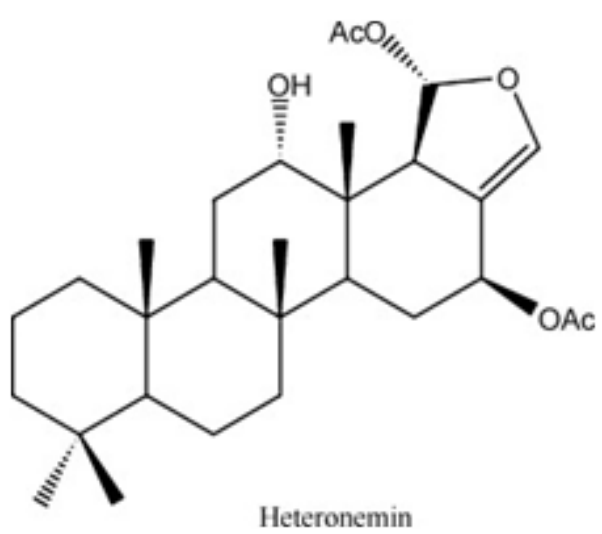

Figure 6: Structure of Hetronemin. 
often secondary metabolites, whose main function is to enable and/ or modulate cellular communication and defense. They are usually produced by functional enzyme clusters in sponges and/or their associated symbiotic microorganisms. Several of them have successfully been approved as antiviral agents for clinical use or have been advanced to the late stages of clinical trials. The most important antiviral lead of marine origin reported thus far is nucleoside Ara-A (vidarabine) isolated from sponge Tethya crypta. It inhibits viral DNA polymerase and DNA synthesis of herpes, vaccinica and varicella zoster viruses [26].

The Hepatitis $C$ virus causes chronic infections in humans, which can develop to liver cirrhosis and hepatocellular carcinoma. Recent research on antiviral compounds isolated 128 molecules from marine invertebrates and microorganisms. The best results were obtained from the extracts produced from the Bacillus sp. isolated from the sponge Petromica citrina. These studied organisms lead to the development of drugs which ensure an alternative therapy for the treatment of hepatitis C [61].

In a recent study a number of pure compounds were isolated from marine sponges and were tested in non-toxic concentrations for virusinfected cells. Norbatzelladine L isolated from a marine sponge of the genus Monanchora displayed antiviral activity against Herpes Simplex virus type (HSV-1), with $97 \%$ of inhibition in the viral adsorption phase [62] (Figure 7).

A sponge-derived bis-indole alkaloid fascaplysin exhibited a broad range of bioactivities including antibacterial, antifungal, antiviral, antiHIV-1-RTase, p56 tyrosine kinase inhibition, antimalarial, anti-angiogenic, antiproliferative activity against numerous cancer cell lines, specific inhibition of cyclin-dependent kinase-4 (IC(50) $350 \mathrm{nM}$ ) and action as a DNA intercalator. A review in 2012, described a great variety of pharmacological studies of fascaplysin and its synthetic analogue [63].

In the last few years over 40 compounds from marine organisms are commercially available in pharmacological markets tested as antiviral drugs. Many more are being tested as potential antiviral drugs at the preclinical and clinical stages. Scientists suggest that the growing interest in marine-derived antiviral compounds, along with the development of new technology in marine cultures and extraction, will continue to be a promising strategy and new trend for modern medicine [64]. In the previous decade more than 150 natural products with promising levels of anti-HIV activity have been isolated following bioassay guided protocols from aqueous or organic extracts of marine organisms. Among the most characteristic marine metabolites that have exhibited significant anti-HIV activity on different biochemical assays designed for chemotherapeutic strategies were sponge metabolites such as avarol, avarone and ilimaquinone [65].

Marine pharmacological literature is reviewed every three years from 1998. The latest peer-review for 2009 to 2011 was published in 2013. The bioactive compounds reviewed were isolated from marine

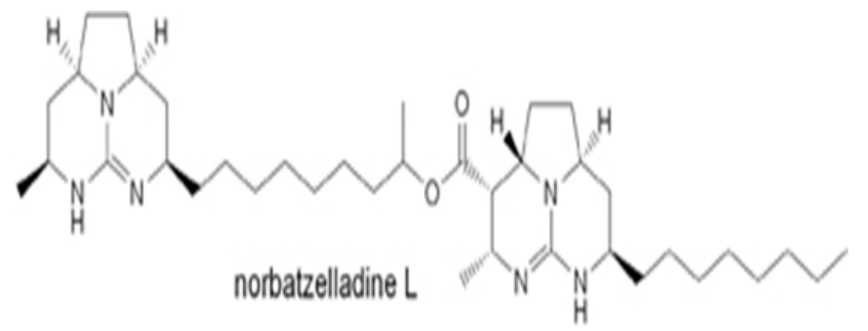

Figure 7: Structure of Norbatzelladine L. animals, sponges, algae, fungi and bacteria. These compounds showed promising antibacterial, antifungal, antiprotozoal, antituberculosis, anti-inflammatory and antiviral activities [66].

\section{Antimalarial Compounds from Sponges}

Several sponge-derived antimalarial compounds have been discovered in the last decade [4]. New discoveries are very promising. Psammaplysin derivatives were identified in the Indonesian marine sponge Aplysinella strongylata. Selected compounds were screened for in vitro activity against chloroquine-sensitive (3D7) P. falciparum malaria parasites. One of the compounds, 19-hydroxypsammaplysin E showed the best antimalarial activity [67] (Figure 8).

Two new pentacyclic ingamine alkaloids [22(S)-hydroxyingamine $\mathrm{A}$ and dihydroingenamine $\mathrm{D}]$, together with the known compound ingamine A, have been isolated from marine sponge Petrosid Ng5 Sp5 (family Petrosiidae). Ingamine and dihydroingenamine D showed strong antiplasmodial activity against chloroquine-sensitive (D6) and -resistant (W2) strains of Plasmodium falciparum. All three compounds also displayed weak antimicrobial and moderate antileishmanial activities [68].

A new bispyrroloiminoquinone alkaloid, tsitsikammamine C, extracted from the marine sponge Zyzzya sp. displayed potent in vitro antimalarial activity. Tsitsikammamine $\mathrm{C}$ inhibited both ring and trophozoite stages of the malaria parasite life cycle. Other compounds, such as makaluvamines and damirones $A$ isolated from the same marine sponge (Zyzzya sp.) displayed potent growth inhibitory activity against both P. falciparum lines [69]. Extracts from the Australian sponge Iotrochota sp. resulted in the purification of two new N-cinnamoylamino acids, iotrochamides A and B. Both compounds were shown to inhibit Trypanosoma brucei brucei [70].

Two new diterpenes isolated from the sponge Stylissa cf. massa, 8-isocyanato-15-formamidoamphilect-11(20)-ene and 8-isothiocyanato-15-formamidoamphilect-11(20)-ene, along with two known derivatives from the same sponge, 8-isocyano-15formamidoamphilect-11(20)-ene and 7-formamidoamphilect11(20),15-diene were proved to exhibit very active antimalarial activity [71]. Nine bromotyrosine-derived compounds were isolated from the Caribbean marine sponge Verongula rigida and screened for their in vitro activity against three parasitic protozoa: Leishmania panamensis, Plasmodium falciparum and Trypanosoma cruzi. Some of the compounds showed potent and selective antiparasitic activity [72]. A new diterpenoid $\beta$-lactam alkaloid, Monamphilectine-A showing potent antimalarial activity, was isolated from a Puerto Rican marine sponge Hymeniacidon sp [73].

Cuban scientists tested the organic fractions of two sponges.

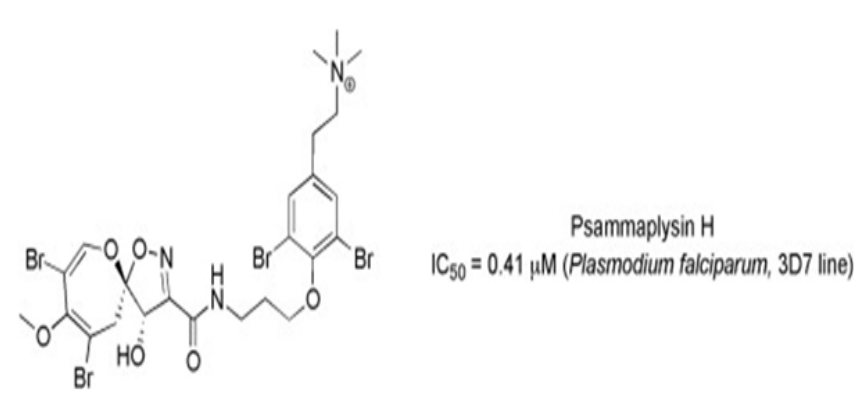

Figure 8: Structure of Psammaphysin $\mathrm{H}$. 
Preparative fractions of Mycale laxissima and Clathria echinata sponges were obtained by reverse-phase flash chromatography. The extracts exhibited promising antimalarial activities in the infection model of C57BL/6 mice with Plasmodium berghei ANKA [74].

\section{Antibiotics from Marine Sponges}

Also, marine sponges were considered for years as a rich source of natural products and metabolites for antibiotics with strong inhibitory activity against bacteria, fungi and microbes Research showed that many bioactive compounds from various sponge species can be useful for the development of new antibiotics and antimicrobial drugs.

In the last five years a number of scientific studies provided evidence for antibiotic, antibacterials and antimicrobial properties in marine sponge's metabolites. Halogenated alkaloids named purpuroines A-J were isolated from the marine sponge Lotrochota purpurea. Tests of these compounds showed inhibitory activity against diseases related to fungi and bacteria [75]. Novel cyclic bis-1,3-dialkylpyridiniums and cyclostellettamines that were isolated from the sponge Haliclona $s p$. from Korea and their structures were determined by spectroscopic techniques. Several of these compounds exhibited moderate cytotoxic and antibacterial activities against A549 cell-line and Gram-positive strains, respectively [76]. New alkaloids, (-)-8'-oxo-agelasine D, ageloxime $\mathrm{B},(+)$-2-oxo-agela-sidine $\mathrm{C}$, 4-bromo- $\mathrm{N}$-(butoxymethyl)$1 \mathrm{H}$-pyrrole-2-carboxamide and (-)-ageloxime $\mathrm{D}$ were isolated from the marine sponge Agelas mauritiana. Some of these metabolites showed antifungal activity against Cryptococcus neoformans, antileishmanial activity in vitro and antibacterial activity against Staphylococcus aureus and methicillin-resistant S. aureus in vitro [77].

Recently, 237 bacteria that were isolated from the marine sponges S. carnosus (Demospongiae) and Leucosolenia sp. (Calcarea). The study showed that $50 \%$ of the isolates from S. carnosus displayed antibacterial activity, and $15 \%$ of the isolates from Leucosolenia sp. demonstrated activity against test fungal strains. The antibacterial activity observed was mostly from Pseudovibrio and Spongiobacter isolates, while the majority of the antifungal activity was observed from the Pseudoalteromonas, Bacillus and Vibrio isolates. According to the researchers, this was the first study in which cultured bacterial isolates from these marine sponges have been evaluated for their antibacterial activity [78].

Extracts from the sponge species Cinachyrella sp., Haliclona sp. and Petromica citrina showed antibacterial activity against $61 \%$ of the coagulase-negative staphylococci (CNS) strains (responsible for causing bovine mastitis), including strains resistant to conventional antibiotics. Extracts from $P$. citrina showed the largest spectrum of inhibitory activity. This study according to the researchers shows the potential of marine sponges to become in the future new sources of antibiotics and disinfectants for the control of CNS involved in bovine mastitis [79]. Diterpene isonitriles isolated from the tropical marine sponge Cymbastela hooperi, and the sesquiterpene axisonitrile-3, isolated from the tropical marine sponge Acanthella kletra, were evaluated in a series of bioassays including anti-fouling, anti-algal, anti-photosynthetic, anti-bacterial (Gram +ve and -ve), anti-fungal, and anti-tubercular. The results of these assays showed that the majority of the tested compounds were active in at least two of the applied test systems [80]. In another recent study marine sponge's sediments and sponge-derived actinomycetes were isolated and tested for bioactive metabolites with antimicrobial and antifungal activity. Nine of the fifteen active extracts were active against multiresistant gram-positive bacterial and/or fungal indicator organisms, including vancomycin-resistant Enterococcus faecium and multidrug-resistant Candida albicans [81].
Bacteria actinomycetes from marine sponges and other marine organisms have been proved prolific producers of pharmacologically important compounds. It is estimated that $70 \%$ of the naturally derived antibiotics that are currently in clinical use are in from actinomycetes (a heterogeneous group of gram-positive, generally anaerobic bacteria). In a recent study Streptomyces sp. strains from Mediterranean sponges and secondary metabolite were screened for anti-infective activities. Isolation and purification of the sponges yielded 3 compounds, namely, cyclic depsipeptide valinomycin, indolocarbazole alkaloid staurosporine and butenolide. All compounds exhibited anti-parasitic activities. According to the researchers, the potential of marine actinomycetes to be used as anti-infective is very promising [82].

\section{Antifouling and anti-Biofilm Compounds from Marine Sponges}

Biofouling organisms such as blue mussels, barnacles, and macroalgae cause serious problems to ships' hulls, cooling systems of power plants, and aquaculture materials. Bacterial biofilms are surface-attached communities of microorganisms that are protected by an extracellular matrix of biomolecules. Long-term use of chemical antifoulants (organic compounds of tin) has led to increased concentrations of tributyltin and caused extensive pollution problems in marine organisms. Natural marine antifouling molecules have recently been reviewed and scientists hope that will provide in the future less toxic and more specific antifouling activity. Sponge-derived antifouling molecules have been found to be less toxic, environmentally friendly biocides and very effective [83].

In the last decade various studies were directed to find the most promising alternative technologies to antifouling in marine organisms and especially from marine sponges. A recent study evaluates the antifouling potential of structurally different compounds containing a 3 -alkylpyridine moiety. The products, namely poly 3 -alkylpyridinium salts, saraine, and haminols, were either extracted or derived from natural sources (the marine sponges Haliclona sp. and Reniera sarai and the mollusc Haminoea fusari), or obtained by chemical synthesis. All these molecules showed generally good anti-fouling activity against larvae of the barnacle Amphibalanus amphitrite. A number of alkaloid derivatives were extracted and isolated from Indonesian marine sponges Agelas linnaei and Ageles nakamurai representing either bromopyrrole or diterpene alkaloids. These compounds exhibited cytotoxic activity. Furthermore, agelasine derivatives inhibited settling of larvae of Balanus improvisus in an anti-fouling bioassay as well as the growth of planktonic forms of biofilm forming bacteria S. epidermidis [84].

A recent review (2011) highlighted the development of small molecules that inhibit and/or disperse bacterial biofilms specifically through non-microbiocidal mechanisms. The review focused on several sets of natural compounds derived from marine sponges [10,85].

\section{Conclusions}

Marine invertebrates are one of the major groups of biological organisms (Porifera, Cnidaria, Mollusca, Arthropoda, Echinodermata, etc) that gave until now significant number of natural products and secondary metabolites with pharmacological properties and led in the formulation of novel drugs. Among marine invertebrates, marine sponges from phylum Porifera is the most dominant group responsible for discovering a large number of natural products, that have been used as template to develop therapeutic drugs. These natural products have a wide range of therapeutic properties, including antimicrobial, antioxidant, antihypertensive, anticoagulant, anticancer, antiinflammatory, wound healing and immune modulator, and other 
Citation: Perdicaris S, Vlachogianni T, Valavanidis A (2013) Bioactive Natural Substances from Marine Sponges: New Developments and Prospects for Future Pharmaceuticals. Nat Prod Chem Res 1: 114 doi: 10.4172/ 2329-6836.1000114

Page 7 of 8

medicinal effects. Therefore, marine sponges are considered a rich source of chemical diversity and health benefits for developing drug candidates, cosmetics, nutritional supplements, and molecular probes that can be supported to increase the healthy life span of humans. In this review we included the most important and highly cited reviews for marine sponge compounds and we presented selected studies of the most important bioactive and promising natural components and secondary metabolites from marine sponges that have been published in the last five years.

\section{References}

1. Higa T, Tanak Ji, Kitamura A, Koyama T, Takahash Mi, et al. (1994) Bioactive compounds from marine sponges. Pure \& Appl Chem 66: 2227-2230.

2. Haefner B (2003) Drugs from the deep: marine natural products as drug candidates. Drug Discov Today 8: 536-544.

3. Belarbi el H, Contreras Gómez A, Chisti Y, García Camacho F, Molina Grima E (2003) Producing drugs from marine sponges. Biotechnol Adv 21: 585-598.

4. Sipkema D, Franssen MC, Osinga R, Tramper J, Wijffels RH (2005) Marine sponges as pharmacy. Mar Biotechnol (NY) 7: 142-162.

5. Alcaraz MJ, Payá M (2006) Marine sponge metabolites for the control of inflammatory diseases. Curr Opin Investig Drugs 7: 974-979.

6. Paul VJ (1992) Ecological Roles of Marine Natural Products. Comstock Press, Ithaca, US.

7. Green G (1977) Ecology and toxicity in marine sponges. Mar Biol 40: 207-215

8. Proksch P (1994) Defensive roles for secondary metabolites from marine sponges and sponge-feeding nudibranchs. Toxicon 32: 639-655.

9. Taylor MW, Radax R, Steger D, Wagner M (2007) Sponge-associated microorganisms: evolution, ecology, and biotechnological potential. Microbiol Mol Biol Rev 71: 295-347.

10. Stowe SD, Richards JJ, Tucker AT, Thompson R, Melander C, et al. (2011) Antibiofilm compounds derived from marine sponges. Mar Drugs 9: 2010-2035.

11. Thompson JE, Walker RP, Faulkner DJ (1985) Screening and bioassays for biologically-active substances from forty marine sponge species from San Diego, California, USA. Mar Biol 88:11-21.

12. Beccero MA, Turon X, Uriz MJ (1997) Multiple functions for secondary metabolites in marine encrusting organisms. J Chem Ecol 23:1527-1547.

13. Becerro MA, Thacker RW, Turon X, Uriz MJ, Paul VJ (2003) Biogeography of sponge chemical ecology: comparisons of tropical and temperate defenses. Oecologia 135: 91-101

14. Muller WEG (2003) Sponges (Porifera) Series, Progress in Molecular and Subcellular Biology/Marine Molecular Biotechnology.

15. Lavrov D (1995) Porifera: Sponges. Tree of Life web project.

16. (2011) Introduction to Porifera. University of California Museum of Paleontology.

17. Molinski TF, Dalisay DS, Lievens SL, Saludes JP (2009) Drug development from marine natural products. Nat Rev Drug Discov 8: 69-85.

18. Simmons TL, Andrianasolo E, McPhail K, Flatt P, Gerwick WH (2005) Marine natural products as anticancer drugs. Mol Cancer Ther 4: 333-342.

19. Gordaliza M (2010) Cytotoxic terpene quinones from marine sponges. Mar Drugs 8: 2849-2870.

20. Hallock YF, Cragg GM (2003) National Cooperative Drug Discovery Groups (NCDDGs): a successful model for public private partnerships in cancer drug discovery. Pharmacol Biol 41: 78-91.

21. Hildebrand M, Waggoner LE, Lim GE, Sharp KH, Ridley CP, et al. (2004) Approaches to identify, clone, and express symbiont bioactive metabolite genes. Nat Prod Rep 21: 122-142.

22. Baker DD, Chu M, Oza U, Rajgarhia V (2007) The value of natural products to future pharmaceutical discovery. Nat Prod Rep 24: 1225-1244.

23. Newman DJ, Cragg GM (2007) Natural products as sources of new drugs over the last 25 years. J Nat Prod 70: 461-477.

24. Newman DJ, Cragg GM (2012) Natural products as sources of new drugs over the 30 years from 1981 to 2010 . J Nat Prod 75: 311-335.
25. Sagar S, Kaur M, Minneman KP (2010) Antiviral lead compounds from marine sponges. Mar Drugs 8: 2619-2638.

26. Villa FA, Gerwick L (2010) Marine natural product drug discovery: Leads for treatment of inflammation, cancer, infections, and neurological disorders. Immunopharmacol Immunotoxicol 32: 228-237.

27. Frota MJ, Silva RB, Mothes B, Henriques AT, Moreira JC (2012) Current status on natural products with antitumor activity from Brazilian marine sponges. Curr Pharm Biotechnol 13: 235-244.

28. Blunt JW, Copp BR, Keyzers RA, Munro MH, Prinsep MR (2013) Marine natura products. Nat Prod Rep 30: 237-323.

29. Shaaban M, Abd-Alla HI, Hassan AZ, Aly HF, Ghani MA (2012) Chemical characterization, antioxidant and inhibitory effects of some marine sponges against carbohydrate metabolizing enzymes. Org Med Chem Lett 2: 30.

30. Longeon A, Copp BR, Quévrain E, Roué M, Kientz B, et al. (2011) Bioactive indole derivatives from the South Pacific marine sponges Rhopaloeides odorabile and Hyrtios sp. Mar Drugs 9: 879-888.

31. Utkina NK (2009) Antioxidant activity of aromatic alkaloids from marine sponges Aaptos aaptos and Hyrtios sp. Chem Nat Compd 6: 849-853.

32. Li Z (2009) Advances in marine microbial symbionts in the China Sea and related pharmaceutical metabolites. Mar Drugs 7: 113-129.

33. Sugiyama $Y$, Ito $Y$, Suzuki M, Hirota $A$ (2009) Indole derivatives from marine sponge-derived yeast as DPPH radical scavengers. J Nat Prod 72: 2069-2071.

34. Kim SK, Dewapriya P (2012) Bioactive compounds from marine sponges and their symbiotic microbes: a potential source of nutraceuticals. Adv Food Nutr Res 65: 137-151.

35. Berrué F, McCulloch MW, Boland P, Hart S, Harper MK, et al. (2012) Isolation of steroidal glycosides from the Caribbean sponge Pandaros acanthifolium. J Nat Prod 75: 2094-2100.

36. Abraham I, El Sayed K, Chen ZS, Guo H (2012) Current status on marine products with reversal effect on cancer multidrug resistance. Mar Drugs 10: 2312-2321.

37. Mayer AM, Glaser KB, Cuevas C, Jacobs RS, Kem W, et al. (2010) The odyssey of marine pharmaceuticals: a current pipeline perspective. Trends Pharmacol Sci 31: 255-265

38. Crews P, Gewick WH, Schmitz FJ, France D, Bair KW, et al. (2003) Molecular approaches to discover marine natural products anticancer leads-An update from a drug discovery group collaboration. Pharmac Biol 41: 39-52.

39. Wang YQ, Miao ZH (2013) Marine-derived angiogenesis inhibitors for cancer therapy. Mar Drugs 11: 903-933.

40. Bergmann W, Feeney RJ (1950) The isolation of a new thymine pentoside from sponges. J Am Chem Soc 72: 2809-2810.

41. Proksch P, Edrada RA, Ebel R (2002) Drugs from the seas - current status and microbiological implications. Appl Microbiol Biotechnol 59: 125-134.

42. Schwartsmann G (2000) Marine organisms and other novel natural sources of new cancer drugs. Ann Oncol 11 Suppl 3: 235-243.

43. Feldman EJ, Lancet JE, Kolitz JE, Ritchie EK, Roboz GJ, et al. (2011) Firstin-man study of CPX-351: a liposomal carrier containing cytarabine and daunorubicin in a fixed 5:1 molar ratio for the treatment of relapsed and refractory acute myeloid leukemia. J Clin Oncol 29: 979-985.

44. Essack M, Bajic VB, Archer JA (2011) Recently confirmed apoptosis-inducing lead compounds isolated from marine sponge of potential relevance in cancer treatment. Mar Drugs 9: 1580-1606.

45. Sipkema D, Osinga R, Schatton W, Mendola D, Tramper J, et al. (2005) Large-scale production of pharmaceuticals by marine sponges: sea, cell, or synthesis? Biotechnol Bioeng 90: 201-222.

46. Newman DJ, Cragg GM (2004) Marine natural products and related compounds in clinical and advanced preclinical trials. J Nat Prod 67: 1216-1238.

47. Halim H, Chunhacha P, Suwanborirux K, Chanvorachote P (2011) Anticancer and antimetastatic activities of Renieramycin $\mathrm{M}$, a marine tetrahydroisoquinoline alkaloid, in human non-small cell lung cancer cells. Anticancer Res 31: 193-201.

48. Guzii AG, Makarieva TN, Denisenko VA, Dmitrenok PS, Kuzmich AS, et al (2010) Monanchocidin: a new apoptosis-inducing polycyclic guanidine alkaloid from the marine sponge Monanchora pulchra. Org Lett 12: 4292-4295. 
Citation: Perdicaris S, Vlachogianni T, Valavanidis A (2013) Bioactive Natural Substances from Marine Sponges: New Developments and Prospects for Future Pharmaceuticals. Nat Prod Chem Res 1: 114 doi: 10.4172/ 2329-6836.1000114

49. Kondracki ML, Guyot M (1987) Smenospongine: a cytotoxic and antimicrobial aminoquinone isolated from smenospongia. Tetrahedron Lett 27: 5815-5818.

50. Kong D, Yamori T, Kobayashi M, Duan H (2011) Antiproliferative and antiangiogenic activities of smenospongine, a marine sponge sesquiterpene aminoquinone. Mar Drugs 9: 154-161.

51. Bai R, Cichacz ZA, Herald CL, Pettit GR, Hamel E (1993) Spongistatin 1, a highly cytotoxic, sponge-derived, marine natural product that inhibits mitosis, microtubule assembly, and the binding of vinblastine to tubulin. Mol Pharmaco 44: 757-766.

52. Rothmeier AS, Schneiders UM, Wiedmann RM, Ischenko I, Bruns CJ, et al. (2010) The marine compound spongistatin 1 targets pancreatic tumor progression and metastasis. Int J Cancer 127: 1096-1105.

53. Valeriote FA, Tenney K, Media J, Pietraszkiewicz H, Edelstein M, et al. (2012) Discovery and development of anticancer agents from marine sponges: perspectives based on a chemistry-experimental therapeutics collaborative program. J Exp Ther Oncol 10: 119-134.

54. Rabelo L, Monteiro N, Serquiz R, Santos P, Oliveira R, et al. (2012) A lactosebinding lectin from the marine sponge Cinachyrella apion (Cal) induces cell death in human cervical adenocarcinoma cells. Mar Drugs 10: 727-743.

55. Schumacher M, Cerella C, Eifes S, Chateauvieux S, Morceau F, et al. (2010) Heteronemin, a spongean sesterterpene, inhibits TNF alpha-induced NF-kappa $B$ activation through proteasome inhibition and induces apoptotic cell death. Biochem Pharmacol 79: 610-622.

56. Shin BA, Kim YR, Lee IS, Sung CK, Hong J, et al. (1999) Lyso-PAF analogues and lysophosphatidylcholines from the marine sponge Spirastrella abata as inhibitors of cholesterol biosynthesis. J Nat Prod 62: 1554-1557.

57. Zhao Q, Mansoor TA, Hong J, Lee CO, Im KS, et al. (2003) New lysophosphatidylcholines and monoglycerides from the marine sponge Stelletta sp. J Nat Prod 66: 725-728.

58. Gunasekera SP, Cranick S, Longley RE (1989) Immunosuppressive compounds from a deep water marine sponge, Agelas flabelliformis. J Nat Prod 52: 757-761.

59. Chairman K, Jeyamala M, Sankar S, Murugan A, Ranjit Singh (2013) Immunomodulating properties of bioactive compounds present inAurora globostellata. Int J Mar Sci 3: 151-157.

60. Kalirajan A, Karpakavalli M, Narayanan KR, Ambiganandham K, Ranjit Singh AJA, et al. (2013) Isolation, characterization and phylogeny of spongeassociated bacteria with antimicrobial and immunomodulatory potential. Int $\mathrm{J}$ Curr Microbiol App Sci 2: 136-151.

61. Santiago Bastos JC, Konecny Kohn L, Fantinatti-Garboggini F, Aiello Padilla M, Furtado Flores E, et al. (2013) Antiviral Activity of Bacillus sp. Isolated from the Marine sponge Petromica citrina against bovine viral diarrhea virus a surrogate model of the hepatitis C virus. Viruses 5: 1219-1230.

62. Kohn LK, Porto PSS, Bianchi BR, C Santos MFC, Berlinck RGS, et al. (2012) NOR-Batzelladine $L$ from the sponge Monanchora sp. displays antiviral activity against Herpes Simplex virus type 1. Planta Med 78-CL27.

63. Bharate SB, Manda S, Mupparapu N, Battini N, Vishwakarma RA (2012) Chemistry and biology of fascaplysin, a potent marine-derived CDK-4 inhibitor. Mini Rev Med Chem 12: 650-664

64. Yasuhara-Bell J, Lu Y (2010) Marine compounds and their antiviral activities. Antiviral Res 86: 231-240.

65. Tziveleka LA, Vagias C, Roussis V (2003) Natural products with anti-HIV activity from marine organisms. Curr Top Med Chem 3: 1512-1535.

66. Mayer AMS, Rodríguez AD, Taglialatela-Scafati O, Fusetani N (2013) Marine Pharmacology in 2009-2011: Marine Compounds with Antibacterial, Antidiabetic, Antifungal, Anti-Inflammatory, Antiprotozoal, Antituberculosis, and Antiviral Activities; Affecting the Immune and Nervous Systems, and other Miscellaneous Mechanisms of Action. Mar Drugs 11: 2510-2573.

67. Mudianta IW, Skinner-Adams T, Andrews KT, Davis RA, Hadi TA, et al. (2012) Psammaplysin derivatives from the Balinese marine sponge Aplysinella strongylata. J Nat Prod 75: 2132-2143.

68. Ilias M, Ibrahim MA, Khan SI, Jacob MR, Tekwani BL, et al. (2012) Pentacyclic ingamine alkaloids, a new antiplasmodial pharmacophore from the marine sponge Petrosid Ng5 Sp5. Planta Med 78: 1690-1697.

69. Davis RA, Buchanan MS, Duffy S, Avery VM, Charman SA, et al. (2012)
Antimalarial activity of pyrroloiminoquinones from the Australian marine spong Zyzzya sp. J Med Chem 55: 5851-5858.

70. Feng Y, Davis RA, Sykes ML, Avery VM, Quinn RJ (2012) lotrochamides A and $B$, antitrypanosomal compounds from the Australian marine sponge lotrochota sp. Bioorg Med Chem Lett 22: 4873-4876.

71. Chanthathamrongsiri N, Yuenyongsawad S, Wattanapiromsakul C, Plubrukarn A (2012) Bifunctionalized amphilectane diterpenes from the sponge Stylissa cf. massa. J Nat Prod 75: 789-792.

72. Galeano E, Thomas OP, Robledo S, Munoz D, Martinez A (2011) Antiparasitic bromotyrosine derivatives from the marine sponge Verongula rigida. Mar Drugs 9: 1902-1913.

73. Avilés E, Rodríguez AD (2010) Monamphilectine A, a potent antimalaria $\hat{i}^{2}$-lactam from marine sponge Hymeniacidon $\mathrm{sp}$ : isolation, structure, semisynthesis, and bioactivity. Org Lett 12: 5290-5293.

74. Mendiola Martínez J, Regalado Veloz CE, Fernández-Calienes Valdés A Acuña Rodríguez D, Rojas Rivero CL, et al. (2012) [In vivo antiplasmodia activity of Mycale laxissima and Clathria echinata sponges]. Rev Cubana Med Trop 64: 244-255.

75. Shen S, Liu D, Wei C, Proksch P, Lin W (2012) Purpuroines A-J, halogenated alkaloids from the sponge lotrochota purpurea with antibiotic activity and regulation of tyrosine kinases. Bioorg Med Chem 20: 6924-6928.

76. Lee Y, Jang KH, Jeon JE, Yang WY, Sim CJ, et al. (2012) Cyclic Bis-1,3 dialkylpyridiniums from the sponge Haliclona sp. Mar Drugs 10: 2126-2137.

77. Yang F, Hamann MT, Zou Y, Zhang MY, Gong XB, et al. (2012) Antimicrobial metabolites from the Paracel Islands sponge Agelas mauritiana. J Nat Prod 75: 774-778.

78. Flemer B, Kennedy J, Margassery LM, Morrissey JP, O'Gara F, et al. (2012) Diversity and antimicrobial activities of microbes from two Irish marine sponges, Suberites carnosus and Leucosolenia sp. J Appl Microbiol 112: 289-301.

79. Laport MS, Marinho PR, Santos OC, de Almeida P, Romanos MT, et al (2012) Antimicrobial activity of marine sponges against coagulase-negative staphylococci isolated from bovine mastitis. Vet Microbiol 155: 362-368.

80. Wright AD, McCluskey A, Robertson MJ, MacGregor KA, Gordon CP, et al. (2011) Anti-malarial, anti-algal, anti-tubercular, anti-bacterial, antiphotosynthetic, and anti-fouling activity of diterpene and diterpene isonitriles from the tropical marine sponge Cymbastela hooperi. Org Biomol Chem 9: 400-407.

81. Engelhardt K, Degnes KF, Kemmler M, Bredholt H, Fjaervik E, et al. (2010) Production of a new thiopeptide antibiotic, TP-1161, by a marine Nocardiopsis species. Appl Environ Microbiol 76: 4969-4976.

82. Pimentel-Elardo SM, Kozytska S, Bugni TS, Ireland CM, Moll H, et al. (2010) Anti-parasitic compounds from Streptomyces sp. strains isolated from Mediterranean sponges. Mar Drugs 8: 373-380.

83. Fusetani N (2004) Biofouling and antifouling. Nat Prod Rep 21: 94-104.

84. Blihoghe D, Manzo E, Villela A, Cutignano A, Picariello G, et al. (2011) Evaluation of the antifouling properties of 3-alyklpyridine compounds. Biofouling 27: 99-109.

85. Hertiani T, Edrada-Ebel R, Ortlepp S, van Soest RW, de Voogd NJ, et al. (2010) From anti-fouling to biofilm inhibition: new cytotoxic secondary metabolites from two Indonesian Agelas sponges. Bioorg Med Chem 18: 1297-1311. 